\title{
Итальянская доктрина международного права (Часть 2. Окончание)
}

Шумилов B.M.*

\author{
(Обзор учебника: Бенедетто Конфорти. \\ «Международное право», \\ 5 издание, изд-во «Эдиторьяле Шьентифика», Неаполь, \\ 1999, 446 стр.; Napoli, 1999)
}

Явление международных организаций. Итак, договоры могут содержать (как было указано выше) не только нормы материальные, но и нормы формальные, т.е. нормы, которые, в свою очередь, вызывают новые правила, являются источниками новых норм, - рамочные, учредительные.

Наиболее важным примером могут служить международные организации. Если конституирующим договором (уставом) международная организация снабжена полномочиями принимать решения, обязательные для государств-участников, то такие решения будут представлять собой источники права «третьего уровня» - источники, рожденные конституирующим договором, вытекающие из договора, основанные на договоре.

Количество международных организаций сегодня является впечатляющим. Впрочем, немногие из них обладают (да и то лишь в отдельных областях) по-настоящему властью принимать обязывающие государства решения. Тем не менее государства постепенно передают международным организациям обязывающие полномочия, последовательно ограничивая собственный суверенитет.

Как правило, в задачи международной организации входит не создавать нормы, а содействовать сотрудничеству между государствами. Многие организации - например ООН - главным образом лишь стимулируют разработку проектов международных договоров, а уж государства самостоятельно решают, брать или не брать на себя обязательства по таким договорам.

- Шумилов Владимир Михайлович - д.ю.н., зав. кафедрой Всероссийской академии внешней торговли. 
Обычно международные организации принимают акты рекомендательного характера, т.е. не являющиеся обязательными для государствучастников. Однако есть и международные организации, например EC, снабженные обязывающей компетенцией.

Решения международных организаций могут приниматься большинством или квалифицированным большинством голосов. В то же время в процессе принятия решений, как правило, ищется консенсус.

Совет Безопасности (СБ) ООН обладает, с точки зрения ratione materiae, ограниченной компетенцией, занимаясь лишь вопросами поддержания мира и международной безопасности. Однако в рамках своей компетенции он вправе принимать обязывающие государства решения. При этом имеется в виду, конечно, что СБ обладает рядом других полномочий (ст. 33-38 Устава ООН), которые реализуются посредством рекомендаций.

Генеральная Ассамблея (ГА) ООН, наоборот, обладает очень широкой компетенцией, но почти не имеет обязывающих полномочий, за исключением полномочий, вытекающих из ст. 17, 18 Устава ООН, по распределению между государствами-членами расходов ООН. Решение о расходах утверждается большинством в $2 / 3$, но является обязательным для всех.

СБ ООН и ГА ООН - это органы ООН, которые состоят из государств. Решения этих органов воплощают в себе волю государств. А вот Генеральный секретарь ООН или судьи Международного суда ООН выступают в личном качестве, а не как представители государств.

В экономической и социальной сфере функционируют международные организации как универсального, так и регионального характера.

К универсальным относятся, в частности, международные организации системы ООН (специализированные учреждения ООН). Они обладают координирующими и контрольными полномочиями.

Специализированные учреждения ООН могут обладать двумя видами функций:

a) нормативными (normative);

б) оперативными (operative), управленческими, например по реализации программ технического содействия, помощи, кредитования и т.п.

Специализированные учреждения ООН издают, как правило, рекомендации либо готовят проекты международных договоров. В ряде случаев, однако, некоторые специализированные учреждения большинством голосов в соответствии с уставами принимают решения, обя- 
зывающие участвующне государства (иногда при условии, что государства в течение определенного периода времени не заявят о непринятии таких решений).

Договоры между ООН и специализированными учреждениями содержат комплекс норм, являющихся составной частью как Устава $\mathrm{OOH}$, так и уставов (конституирующих договоров) специализированных учреждений. Этот комплекс норм направлен на то, чтобы дисциплинировать соответствующие органы. И, соответственно, нарушение таких норм либо со стороны ООН, либо со стороны специализированного учреждения будет рассматриваться не как нарушение договорных обязательств, а как основание для недействительности резолюции (решения) того или иного органа.

Ниже следуют примеры международных организаций (специализированных учреждений $\mathrm{OOH}$ ), которые в соответствии со своими уставами вправе издавать акты, обязывающие участвующие государства, т.е. акты - источники права «третьего уровня».

ИКАО - Международная организация гражданской авиации. В соответствии с конституирующим актом (ст. $37,54,90$ ) исполнительный орган Совет ИКАО вправе издавать в форме приложений нормы международные стандарты воздушного транспорта. Каждое такое приложение принимается большинством в $2 / 3$ и вступает в силу для всех государств-членов по истечении 3 месяцев, если со стороны большинства государств - членов ИКАО не будет заявлено о непринятии приложения.

Таким образом, каждое такое приложение - это настоящий источник права, так как речь идет об акте, обязательном для всех государствчленов, включая государства, не согласившиеся с ним.

ВО3 - Всемирная организация здравоохранения. В соответствии с конституирующим актом (ст. 21, 22) Ассамблея ВОЗ вправе издавать большинством в 2/3 голосов регламенты, касающиеся, например, порядка предупреждения эпидемий, характеристик лекарственных препаратов и т.п.

Регламенты вступают в силу для всех государств - членов ВО3, кроме государств, которые в течение определенного периода времени не заявят о непринятии регламента.

Международный союз электросвязи. В соответствии с нормами, добавленными в конституирующий акт Конвенцией 1982 г., Союз вправе большинством голосов принимать регламенты, обязательные для государств-членов. 
МВФ - Международный валютный фонд. Совет управляющих МВФ принимает решения большинством голосов на основе взвешенного голосования: каждое государство-участник обладает разным количеством голосов, в зависимости от размера его квоты в капитале Фонда. США обладают самой большой квотой.

В рамках МВФ осуществляется сотрудничество в международной финансовой системе, поддерживаются валютные курсы и равновесие платежных балансов.

Государства - участники МВФ имеют право при неравновесии платежных балансов прибегать к валютным резервам Фонда - в пределах, зависящих от их квоты в капитале, и на согласованных условиях.

Условия кредитования государств из средств Фонда содержатся в соглашениях - так называемых stand-by agreements, а также в «письмах о намерениях» (lettera di intenti).

В «письма о намерениях» включаются, например, те или иные условия, касающиеся национальной экономики государства-заемщика.

ИФАД-Международный фонд сельскохозяйственного развития. Решения в ИФАД принимаются большинством голосов.

В целом Фонд находится под преобладающим влиянием развивающихся стран (прежде всего стран - членов ОПЕК, которым принадлежит $2 / 5$ уставного капитала).

ВТО - Всемирная торговая организация. Интересно взглянуть на ВТО с точки зрения процесса принятия решений (хотя ВТО и не является специализированным учреждением $\mathrm{OOH}$ ).

В соответствии со ст. IX Соглашения об учреждении ВTO в Организации могут приниматься решения, обязывающие участвующие в ВТО государства. Так, например, Конференция министров и/или Генеральный совет вправе принимать большинством в 3/4 голосов решения, касающиеся толкования многосторонних торговых соглашений пакета ВТО, временного освобождения государств от того или иного обязательства по уставу и т.п.

Кроме того, действующий в системе ВТО Орган по урегулированию споров может в соответствующих случаях разрешать применение контрмер в отношении государства - члена ВТО.

Европейский Союз. Три Сообщества - ЕЭС, ЕОУС и Евратом изначально обладали сушественной компетенцией принимать решения, обязательные для государств-членов.

Решения, принимаемые внутри Сообществ, были и остаются самым 
ярким примером источников МП, порожденных конституирующими Сообщества договорами.

Будучи самостоятельными и автономными, Сообщества функционируют через обшие органы - Совет и Комиссию. При этом Европейское экономическое сообщество (в соответствии с Маастрихтским договором) стало называться Европейским Сообществом.

По Маастрихтскому договору (вошел в силу 1 ноября 1993 г.) на основе трех Сообшеств был создан Европейский Союз для совместных действий государств-участников в сфере внешней политики и для сотрудничества в сфере юстиции и внутренних дел.

Государства - участники ЕС передали органам ЕС большое число полномочий, входивших ранее во внутреннюю компетенцию государств, для того, чтобы обеспечить сближение внутренних правовых систем.

Существует две точки зрения на природу ЕС. С одной стороны, считается, что речь идет о настоящих международных организациях. С другой стороны, утверждают, что ЕС - это фрагменты формирующегося федеративного государства.

Действительно, ЕС не похож на классические международные организации. Например, состав Комиссии формируется в личном качестве, а не из представителей государств; Парламент ЕС формируется путем всеобщих и прямых выборов. В ЕС действует принцип, характерный для федеративных государств: приоритет права ЕС над внутренним правом государств-членов.

И все-таки ЕС остается - по крайней мере сегодня - международной организацией (комплексом международных организаций), но с очень сложной системой. Чтобы подчеркнуть особенности Сообществ, их часто называют не международными, а надначиональными организациями.

Договором об учреждении ЕС (ст. 189) предусмотрены следующие виды актов, принимаемых в ЕС: регламенты, решения, директивы, рекомендации и заключения. Последние два вида актов - рекомендации и заключения - не являются обязывающими актами.

Посредством регламентов право ЕС заменяет или определяет внутреннее право государств-членов. Регламенты обязательны для государств во всех своих частях и применяются напрямую в каждом государстве EC.

Регламенты содержат нормы обшего, абстрактного, рамочного характера и адресуются не только государствам, но и частным лицам. 
Решения содержат нормы конкретного характера, могут адресоваться одному государству или частному лицу. Они также обязательны для всех, кому адресованы.

Директивы обязательны для государств-членов лишь в том, что касается результата, который требуется достичь; формы и средства достижения этого результата определяются самостоятельно самими государствами.

Рекомендации международных органов. Типичными актами, принимаемыми органами международных организаций, являются рекомендации, не носящие обязывающего государства характера. В этом смысле рекомендации не являются источниками МП. И тем не менее они влекут за собой определенные - вторичные - юридические последствия, юридический эффект: эффект наделения правомерностью, придания легитимности.

Иерархия источников МII. На вершине иерархии источников МП находятся, таким образом, нормы международных обычаев, в том числе особая категория обычно-правовых норм, состоящая из общих принципов права.

Международный обычай - это источник «первого уровня»; единственный источник норм общего международного права, связывающих все государства.

Договор - это источник «второго уровня». Обязательность норм договора основана на международно-правовом обычае pacta sunt servanda.

На третьем уровне находятся источники, предусмотренные договорами, в том числе акты международньх организаций.

При этом нормы международных обычаев - очень гибкие. Они могут заменяться нормами договоров, и в этом случае договорные нормы будут носить характер ratione personarum, т.е. связывать только участников договора.

В то же время нормы международного обычая носят общий характер, а договорные нормы - как правило, конкретный характер.

Поскольку конкретные нормы имеют приоритет над общими, В конечном итоге договорные нормы получают приоритет над обычно-правовыми нормами (кроме случаев, когда обычай формируется как отклонение от договорной нормы).

Нормы международного договора не должны и не могут противоречить императивным нормам общего МП (jus cogens). Впрочем, ни док- 
трина, ни практика не дают общих критериев относительно того, что считать нормами јus cogens.

Представляется, что сложился международно-правовой обычай, в силу которого таковыми являются принципы Устава ОOH.

Действие международного права. Предметная сфера современного МП необычайно широка. Оно все глубже проникает в вопросы, которые когда-то были строго зарезервированы только за внутренним правом государств.

Главная идея всего МП (и его обычно-правовой, и договорной частей) состоит в том, чтобы установить пределы, границы для применения силы со стороны государства как вовне, так и внутри своей территории.

При этом классическая свобода действий государства на своей территории ограничена определенными рамками, которых следует придерживаться, например по отношению к иностранцам и их имушеству, к органам иностранных государств, международным организациям.

Одним из обычно-правовых принципов является обязанность защиты иностранцев и их имущества государством пребывания.

Фундаментальной обычно-правовой нормой, затрагиваюшей разграничение юрисдикций различных государств, является норма о территориальном суверенитете. Эта норма сложилась еще во времена Священной Римской империи. В эпоху абсолютных монархий данная норма существовала как нечто вроде «права собственности государства» (diritto di proprieta dello Stato), а точнее - суверена. Объектом права собственности выступала территория. Власть государства над людьми была производной от права собственности на территорию.

В современном понимании норма о территориальном суверенитете предоставляет каждому государству право осуществлять исключительным образом свою власть над территориальным сообществом, т.е. над индивидами, находящимися на территории, и их имуществом.

Территориальный суверенитет сегодня находится под защитой другого фундаментального принципа МП - запрета на применение силы и на угрозу ее применения.

С территориальным суверенитетом связан принцип невмешательства во внутренние и внешние дела других государств, на который часто ссылаются в дипломатической практике и юридическое содержание которого трудно определить. С утверждением других принципов этот принцип потерял свою автономию, растворился в них, оказался 
«перекрыт» ими, в частности принципом запрета на применение силы и угрозы силой.

Вопросы иммунитета и юрисдикции. Когда речь идет о пределах свободы одного государства в отношении другого государства, возникает вопрос и о гражданско-правовой юрисдикции: может ли государство предстать перед судом другого государства за нарушение гражданско-правового обязательства или государство и в этом случае защищено иммунитетом?

Итальянское правосудие, например, долгое время (особенно после первой мировой войны) придерживалось принципа «абсолютного иммунитета», но постепенно пришло к принципу «ограниченного (или относительного) иммунитета», который сегодня можно считать общепринятым.

Согласно принципу «ограниченного иммунитета» государство не подлежит гражданско-правовой юрисдикции другого государства в случае, если осуществляло публичные функции, и, наоборот, не имеет иммунитета, если осуществляло действия частноправового характера (купля-продажа недвижимости в порядке инвестиций, выпуск облигационных займов и т.п.).

Помимо классических рамок, ограничивающих свободу действий государств в отношении иностранцев и иностранных государств, МП знает и другие ограничения свободы действий государства на своей территории.

Сфера внутренней компетенции государств (dominio riservato) постоянно подвергается эрозии. Традиционно в сферу внутренней компетенции входили отношения между государством и его гражданами, организация и функции органов власти, экономическая и социальная политика государства и т.п.

Если в международном обычном праве еще сохранилось понятие внутренней компетенции, то в международном договорном это понятие утратило свое значение. Так, в договорном порядке свобода действий государства на собственной территории (сфера внутренней компетенции) ограничена, в частности, в таких вопросах, как:

- права человека;

- сотрудничество государств в целях развития;

- либерализация внешней торговли;

- региональная экономическая интеграция;

- антимонопольное законодательство; 
- права на интеллектуальную собственность;

- унификация частного права (гражданского и торгового права);

- экстрадиция, правовая помощь, взаимное признание судебных и арбитражных решений;

- налогообложение - и др.

США посредством антитрестовского законодательства и торговых бойкотов пытаются возлагать обязательства на предприятия (юридические лица), находяшиеся за пределами страны по всему миру, угрожая предприятиям в случае нарушений применить санкции против их имущества и интересов.

Подобные претензии проявились при эмбарго, примененном США в отношении газопровода из СССР в Европу (1981-1982 гг.), в Законе Хэлмса - Бэртона 1996 г. "Cuban Liberty and Democratic Solidarity Act", в мерах, предпринятых против Ирана, Ливии. Эта линия США встретила жесткую оппозицию со стороны Европейского Союза (Регламент Совета ЕС № 2271/96 от 22 ноября 1996 г.).

Международное обычное право запрещает распространять юрисдикцию государства на иностранцев при отсутствии адекватной связи с данным территориальным сообществом.

Государство и ресурсы. Свобода действий государств на своей территории предполагает, что государство вправе использовать свои природные ресурсы. Однако при этом не должен наноситься ущерба территории другой страны (или, например, иностранным кораблям, самолетам в открытом море и в воздушном пространстве над открытым морем).

Из международного обычая проистекает норма, обязывающая государства не совершать действий, влекущих вред другим государствам.

Бывает, что деятельность с использованием разного рода ресурсов в пределах одного государства имеет неблагоприятные последствия на территории другого государства (атомные электростанции, выбросы химических вешеств в атмосферу и т.п.). Принцип ответственности, который во внутреннем праве выражается фразой «кто наносит ущерб - платит», является и принципом МП, закрепленным в различных международных договорах. В международном сообществе прослеживается линия на формирование международно-правовой обязанности государств рационально управлять ресурсами на своей территории с учетом требований защиты окружающей среды и интересов будущих поколений. 
Международное морское право, международное воздушное право, международное космическое право. Пределы власти государств на морских пространствах определяются в рамках международного морского права. По модели норм морского судоходства в значительной степени создаются и нормы воздушной навигации, которые прошли путь становления через международный обычай.

В основу международного воздушного права заложены два главных принципа. Первый вытекает из статьи 1 Чикагской конвенции 1944 г: суверенитет государств распространяется на воздушное пространство над государственной территорией и территориальным морем. Второй принцип: все остальное воздушное пространство является свободным для использования любой страной.

Государства осушествляют юрисдикцию над воздушными судами своей национальности (то есть своей регистрации). Государства определяют правила полета над своей территорией, устанавливают воздушные коридоры, зоны, запрешенные для пролета. Во время пролета иностранного самолета вся его бортовая жизнь находится под контролем государства, через воздушное пространство которого самолет летит.

С увеличением скорости летательных аппаратов появилась практика установления так называемых «зон идентификации» - 30н, находящихся за десятки и сотни километров в воздушном пространстве над открытым морем, примыкающих к побережью государства. Прибрежные государства требуют от направляющихся в их сторону иностранных воздушных судов, чтобы они идентифицировали себя и стали под контроль наземных служб. В противном случае такие воздушные суда принуждаются к посадке или даже сбиваются.

Нормы, регулирующие деятельность в космическом пространстве, развивались по аналогии с принципом свободы полета над «ничейными» пространствами. Государство, запустившее спутник или космический корабль, обладает исключительными правами на них.

Природные ресурсы космоса заключаются в возможности использования пространства для радиосвязи и телекоммуникаций. Государства обладают свободой использования космического пространства для этих целей. Проблема состоит в том, что некоторые возможности являются ограниченными. Например, на геостационарной орбите можно разместить максимум 1800 спутников. В этом случае не действует принцип «первого пришедшего»; государства должны координировать эти вопросы. 
В прошлом со стороны группы экваториальных государств (Бразилия, Конго, Эквадор, Индонезия, Кения, Уганда, Заир и Колумбия) была произведена попытка установить свой суверенитет над геостационарной орбитой. Эти государства выступили с Боготской декларацией 1976 г. Однако декларация встретила противодействие большинства государств и не имела конкретных последствий.

Режим полярных пространств. Полярные пространства Земли не подпадают под суверенитет ни одного государства, хотя претензий на это было много.

Что касается Антарктиды, то это, согласно Вашингтонскому договору 1959 г., «интернационализированная» территория.

Что касается Арктики, то в отношении нее была выдвинута «доктрина секторов», в соответствии с которой государства, примыкающие к полярному кругу, обладают суверенитетом в отношении сухопутных и морских пространств в секторе от их побережья к полюсу. Претензии приполярных государств на суверенитет в отношении соответствуюших секторов всегда отвергались большинством государств, в том числе и Соединенными Штатами, одним из приполярных государств. Эти претензии безосновательны.

Над полярными пространствами нет суверенитета какого-либо определенного государства. Каждое государство располагает юрисдикцией в отношении образуемого в таком регионе сообшества (направляемого судна, научной экспедиции, морской платформы и т.п.).

Применение международно-правовых норм на национальной территории. В процессе применения норм МП во внутреннем правопорядке первостепенное место принадлежит юридическому корпусу, прежде всего судьям и юристам из государственного аппарата.

Внутреннее право должно быть «подлажено» под право международное. Эта задача почти во всех государствах решается одинаковыми средствами. Правда, при этом согласование внутреннего права с международным происходит не любой ценой. Государства посредством своего внутреннего права защищают определенные национальные ценности, закрепленные на конституционном уровне. Применение международного права преломляется через эти ценности.

В то же время нельзя защищать любые национальные ценности любой ценой, особенно ценности националистического порядка. Ценности международные - выше; речь идет о международном сотрудничестве и международной солидарности (solidarieta). 
Средства адаптации внутреннего права к международному. Различают традиционные и специальные средства адаптации внутреннего права к международному.

Традиционный способ - когда международно-правовые нормы воспроизводятся во внутреннем праве (в конституционных, законодательных, подзаконных актах). Специальный способ - когда внутреннее право отсылает к международному. Этот способ имеет множество преимуществ и предпочтителен, поскольку смещает центр тяжести в правоприменении с праводателя на правоприменителя.

Отсылка очень широко применяется в практике Италии и в других странах. Важное исключение составляет Великобритания, где по преимуществу используется традиционный способ имплементации.

Когда нормы МП имплементированы во внутренний правопорядок, они становятся источником прав и обязанностей для всех субъектов внутреннего права, как и любая правовая норма внутреннего происхождения. Точнее, международно-правовые нормы, можно сказать, исчезают, а вместо них появляются соответствующие внутренние нормы. Международно-правовые нормы как бы «национализируются».

Впрочем, бывают ситуации, когда традиционный способ имплементации просто необходим: когда международно-правовую норму нельзя применить напрямую, а требуются определенные внутренние мероприятия.

В связи с этим различают нормы самоисполнимые (self-executing) и несамоисполнимые (non self-executing). Самоисполнимыми являются нормы, которые не требуют принятия специальных внутренних мер и применяются напрямую. Для реализации несамоисполнимых норм требуется, как правило, создание определенных органов или процессуальных правил.

Примером несамоисполнимых норм может служить статья 20 Европейской социальной хартии 1961 г., в которой участвует Италия). Хартия предоставляет каждому государству-участнику возможность выбрать пять статей и считать себя связанным только этими статьями.

В международной жизни ощущается тенденция - использовать в политических целях различие между самоисполнимыми и несамоисполнимыми нормами, а именно для того, чтобы не исполнять «нежелательные» нормы.

Об иерархии имплементированных норм. Имплементированные во внутренний правопорядок нормы МП могут занимать различное 
место в иерархии норм. Если, например, нормы МП «вошли» через конституцию, то они приобретают высшую юридическую силу, становятся частью конституционного права.

Нормы МП могут войти во внутреннее право посредством закона или подзаконного акта и занять место в иерархии норм в соответствии с этим.

В Италии верховенство общего международного права подтверждено на конституционном уровне (ст. 10 Конституции Италии).

Международные правонарушения. Что такое противоправный факт в международном праве (fatto illecito internazionale)? Каковы его элементы?

Проблематикой международных правонарушений и международной ответственности государств с 1953 г. занималась Комиссия международного права $\mathrm{OOH}$, завершившая эту кодификационную работу в $1996 \mathrm{r}$.

С точки зрения субъектного элемента, противоправный факт выражается в поведении одного или нескольких органов государства. При этом такой орган или органы могут быть частью законодательной, судебной или исполнительной власти как в центре, так и в регионах страны.

Органом государства считаегся и любое должностное лицо, которое наделено властными полномочиями. Государство несет ответственность также и за действия органа, который, совершая правонарушение, превысил свои полномочия, как они определены внутренним правом. Государство несет ответственность и за противоправные действия частных лиц в отношении иностранцев, иностранной собственности и иностранного государства, если не расследует действия частных лиц и не наказывает их.

Предлетно-объектным элементом правонарушения является противоправность поведения органа государства. В этой связи различают, например, два вида правонарушения:

a) один вид правонарушения представляет собой нарушение обязанности обеспечить результат;

б) другой вид - нарушение обязанности использовать определенные средства.

Обязанность, ориентированная на результат, и обязанность, ориентированная на средства, - вот два критерия.

Примером обязанности, ориентированной на средства, является обязанность подводных лодок, находясь в территориальном море иност- 
ранного государства, плыть в надводном положении. Примером обязанности, ориентированной на результат, может служить обязанность обеспечить защиту иностранцев. Преобладаюшая часть МП, особенно нормы международных обычаев, ориентированы на результат.

Кроме того, среди правонарушений различают:

а) международные преступления;

б) международные деликты.

К международным преступлениям относятся, например, агрессия, геноцид, апартеид, т.е. грубое нарушение обязанностей фундаментального характера. В случае международного преступления пострадавшим считается любое государство, а не только государство, непосредственно пострадавшее от преступления. А это означает, что право на противодействие (на своеобразную «коллективную самозащиту») получает любое государство, в том числе государство, прямо не затронутое преступлением.

Вопрос взаимности. Во внутренний правопорядок встроен механизм взаимности, означающий, что иностранному государству, его органам и гражданам предоставляется такой режим, какой в иностранном государстве предоставляется государству-контрагенту, его органам и гражданам.

Одностороннее ухудшение правового режима дает основание государству-контрагенту в силу принципа взаимности предпринять контрмеры. Следовательно, взаимность выступает в качестве юридической основы для ввода контрмер.

Международные споры и международное правосудие. Государства обладают правом вынести любой свой спор в соответствующий международный суд. Международный спор - это разногласие по поводу юридического или фактического обстоятельства, столкновение юридических позиций либо интересов между субъектами МП. Не существует споров, заведомо неприемлемых для процедур правосудия.

Международный спор юридический отличается, по мнению некоторых юристов, от международного спора политического тем, что в политическом споре стороны стараются не столько опереться на международное право, сколько изменить его в свою пользу.

Международное правосудие и международный процесс в современном мире носят главным образом арбитражный характер. Некоторые международные суды ограниченной компетенции не меняют картину; они тоже по сушеству являются арбитражами (за отдельными исклю- 
чениями - вроде Суда ЕС). Ни один международный судья не может вынести решения, если его юрисдикция предварительно не принята сторонами спора. До сих пор даже уяснение, толкование международно-правовых норм осуществляется юристами во внутреннем правопорядке. Возможно, поэтому внутреннеправовой аспект все еще превалирует над международно-правовым, когда речь заходит о применении норм МП.

Институт международного судопроизводства/арбитража проделал заметную зволюцию во второй половине XX века, хотя и не затронул фундаментальной основы - добровольного характера обращения к международному правосудию.

Прежняя практика обращения к международному арбитражу была следующей. В случае спора между государствами спорящие стороны заключали арбитражное соглашение (так называемый «арбитражный компромисс»), назначали арбитра, которым мог быть глава какого-либо государства, или коллегию арбитров, формулировали некоторые процедурные правила и брали обязательство уважать вынесенное решение. Решение зачастую содержало только резолютивную часть и вовсе не содержало мотивировочной части.

Современный международный арбитражный (судебный) процесс ушел заметно дальше: формализованы требования к форме арбитражного решения, более детализированным стало арбитражное соглашение, произошла институционализация арбитражных коллегий. Так, например, Международный суд ООН представляет собой очень высокую степень институционализации всех сторон международного процесса: в нем действует постоянный корпус судей, существуют жесткие правила процедуры, которые не могут быть изменены сторонами спора. Однако и здесь споры рассматриваются лишь в том случае, если на это согласны стороны спора.

Заключение. Нет сомнения, что более-менее системное знакомство с доктриной международного права, изложенной Б. Конфорти, является полезным и содержательным для российских юристов, специалистов-практиков, студентов, преподавателей.

С отдельными положениями итальянского юриста-международника можно согласиться; некоторые аспекты вызывают возражения и контраргументы. Так, например, отмечается, что международное право это право надгосударственное; право международного сообщества; право, которое регулирует одновременно и межгосударственные, 
и межличностные отношения. Представляется, что итальянский автор увидел в международном праве некие новые качественные моменты и приписал их самому международному праву. На самом деле эти новые моменты есть проявление более широкой реальности - формирования Глобального права, которое состоит или будет состоять из ряда компонентов: международного права, внутреннего права государств, наднационального права и транснационального права (о концепции Глобальной правовой системы см. журналы ««Московский журнал международного права», № 4, 2002; «Юрист-международник», № 3, 2003).

Есть в изложенном материале и рассуждения, требующие дополнительного обдумывания. Часть приводимых примеров вполне может быть использована в преподавательской и научной работе.

Как бы то ни было, Б. Конфорти добавит пищи для размышления и информации для всех, кто работает над проблемами международного права. 